\title{
Study of Molecular Interactions in Binary Mixtures of Diethyl Carbonate + Benzene Derivatives at Different Temperatures
}

\author{
K. Narendra ${ }^{1, *}$, B. Sudhamsa ${ }^{2}$, M. Sarath Babu ${ }^{2}$ and T.S. Krishna ${ }^{3}$ \\ ${ }^{1}$ Department of Physics, V.R. Siddhartha Engineering College (Autonomous), Vijayawada, India \\ ${ }^{2}$ Department of Chemistry, MIC College of Technology, Kanchikacharla, India \\ ${ }^{3}$ Department of Physics, Rayalaseema Univeristy, Kurnool, India
}

\begin{abstract}
Investigation on the molecular interactions between binary mixtures containing diethyl carbonate in combination with nitrobenzene, chlorobenzene and aniline is presented. Ultrasonic velocity and density values were determined for the individual components as well as binary mixtures of the above benzene derivatives with diethyl carbonate at temperatures $(293.15,298.15,303.15,308.15,313.15,318.15$ and 323.15$) \mathrm{K}$ over the entire composition range. Further, adiabatic compressibility and acoustic impedance values were calculated using the experimental results. In addition to these parameters, the excess parameters like excess adiabatic compressibility, excess acoustic impedance and deviation in ultrasonic velocity were also obtained. Based on all these results, molecular interactions among the selected components were discussed.
\end{abstract}

Keywords: Ultrasonic velocity, density, molecular interactions, binary mixtures, diethyl carbonate.

\section{INTRODUCTION}

Valuable information about molecular structure, packing of the constituent molecules and interactions among them at different conditions of temperatures and concentrations can be obtained by studying changes in ultrasonic velocity, density and other thermo-acoustical parameters. Moreover, accurate experimental data on such parameters of organic compounds and their binary combinations are necessary in many chemical industries and engineering disciplines.

Compare to the other techniques like dielectric relaxation [1], infrared spectroscopy, nuclear magnetic resonance, etc. acoustical or ultrasonic methods are used as complimentary because of sensitive to very low population densities at high energy states, and have the added advantage of being less cost with efficiency.

The study of changes in thermo-acoustical properties of mixtures of organic compounds and the degree of deviation from ideality is an excellent qualitative and quantitative method to derive useful information about structural alignments and intermolecular forces in liquid mixtures. This fact has motivated both the theoretical and the experimental investigations of excess thermodynamic properties of liquid mixtures [2,3]. Further, dynamic behavior of liquids can be studied by using accurate measurement of energy changes due to scattering [4].

${ }^{*}$ Address correspondence to this author at the Department of Physics, V.R. Siddhartha Engineering College (Autonomous), Vijayawada, India;

Tel: +9198850 38074; E-mail: narenk75@gmail.com
In the recent past, study of thermodynamic and thermo-acoustic properties of binary systems containing esters of carbonic acid received much attention. In view of the increased significance of esters of carbonic acid, the authors of the present study reported earlier the investigations on binary mixtures containing diethyl carbonate [5]. Interesting results obtained in this study led the authors continue their investigations on diethyl carbonate with simpler benzene derivatives like nitrobenzene, chlorobenzene and aniline. These compounds have been selected in view of their industrial importance summarized below.

Many chemical industries like pharmaceutical industry, agrochemical industry, hydrogen refinery, etc., use diethyl carbonate (DEC) as an extraction solvent and reaction medium. In dyeing industry, it can make the dyeing process uniform and resists fading against sunshine. It is also famous for its action as paint remover in paint industry. DEC also acts as a lubricant of the new refrigerant, hydrofluorocarbon. Aniline is used as precursor in chemical production industries like rubber processing chemicals, drugs, dyes, pigments, herbicides and explosives. About $95 \%$ of nitrobenzene produced industrially is used for manufacturing aniline. Also, it is used fin leather dressings, floor and shoe polishes and as a solvent in paint industry.

It is useful in masking unpleasant odors. It finds application as an inexpensive perfume for soaps and in Kerr cells. The major use of chlorobenzene is in rubber dyestuffs and herbicides.

Identifying the industrial importance of diethyl carbonate, some researchers [6, 7] studied molecular 
interactions in binary liquid mixtures containing diethyl carbonate. Based on this background, the binary systems namely, "diethyl carbonate + nitrobenzene", "diethyl carbonate + chlorobenzene" and "diethyl carbonate + aniline" are chosen for the present study. For each of these binary mixtures, the parameters namely, speed of sound, density, excess acoustic impedance $\left(Z^{\mathrm{E}}\right)$, excess adiabatic compressibility $\left(\beta^{\mathrm{E}}\right)$ and deviation in speed of sound $(\Delta \mathrm{U})$ were determined at $(293.15,298.15,303.15,308.15,313.15,318.15$ and 323.15) $\mathrm{K}$ over the entire range of composition. The excess/deviation values were correlated with the Redlich-Kister equation. All the results are interpreted in terms of intermolecular interactions.

\section{MATERIALS AND METHODS}

All the chemicals used in this study were $>99 \%$ pure supplied by Sigma Aldrich Chemical Company. The purity of these chemicals was checked by measuring the density and speeds of sound and comparing these values with those reported in literature. The chemicals were used as such in the present study without carrying out any purification process.

Density and speed of sound of pure liquid components and of liquid mixtures were measured by Anton Paar DSA 5000 density and sound analyzer provided with two Pt 100 platinum thermometer. In view of extreme sensitivity of density towards temperature, a built-in solid state thermostat was equipped with the apparatus, with a readability of $0.001 \mathrm{~K}$. The accuracies in the density and speed of sound reported are $5 \times 10^{-3} \mathrm{Kgm}^{-3}$ and $0.5 \mathrm{~ms}^{-1}$ respectively.

Binary liquid mixtures were prepared by mixing known masses of pure liquids and were stored in airtight-stoppered bottles to minimize losses due to evaporation. For all weighing, an electronic balance with a precision of $\pm 0.01 \mathrm{mg}$ was used.

\section{RESULTS AND DISCUSSION}

The experimental ultrasonic velocity and density values obtained from the measurements of the pure compounds are summarized in Table 1 along with the corresponding literature values [8-12]. A good agreement is observed between experimental and literature values. The experimental ultrasonic velocity and density values for the binary mixture at different temperatures and at atmospheric pressure are summarized in Table 2. Adiabatic compressibility and acoustic impedance were calculated from our measurements by using the following equations.

Adiabatic compressibility,

$\beta=1 / \rho U^{2}$

Acoustic impedance,

$Z=U . \rho$

where, $u$ and $\rho$ are the ultrasonic velocity and density respectively.

The excess properties such as $\beta^{\mathrm{E}}$ and $\mathrm{Z}^{\mathrm{E}}$ have been calculated using the equation

$Y^{E}=Y_{\text {mix }}-\left[x_{1} Y_{1}+x_{2} Y_{2}\right]$

where $Y^{E}$ is $\beta^{E}$ or $Z^{E}$, and $x$ represents mole fraction of the component and subscripts 1 and 2 stand for the components 1 and 2 .

The excess values for each mixture have been fitted to Redlich-Kister [13] polynomial equation

$$
Y^{E}=X_{1} \cdot X_{2} \sum_{i=0}^{n} A_{i}\left(X_{1}-X_{2}\right)^{i}
$$

The values of the coefficients $A_{i}$ were calculated by method of least squares along with the standard deviation $\sigma\left(\mathrm{Y}^{\mathrm{E}}\right)$. The coefficient is adjustable parameters for a better fit of the excess functions. The standard deviation values were obtained from

Table 1: Comparison of Experimental Values of Ultrasonic Velocity and Density with Literature Values at $303.15 \mathrm{~K}$

\begin{tabular}{|c|c|c|c|c|}
\hline \multirow{2}{*}{ Compound } & \multicolumn{2}{|c|}{ Ultrasonic velocity, u (m/s) } & \multicolumn{2}{|c|}{ Density $\left(\mathbf{k g} / \mathbf{m}^{3}\right)$} \\
\cline { 2 - 5 } & Experiment & Literature & 963.468 & Experiment \\
\hline \hline Diethyl carbonate & 1156.96 & -- & 1192.297 & $1193.4[9]$ \\
\hline Nitrobenzene & 1438.30 & $1432.8[10]$ & 1095.506 & $1095.0[9]$ \\
\hline Chlorobenzene & 1248.92 & $1252.0[11]$ & 1012.746 & $1013.23[12]$ \\
\hline Aniline & 1617.52 & $1619.3[12]$ & \multicolumn{2}{c}{$18]$} \\
\hline
\end{tabular}


Table 2: Experimental Values of Ultrasonic Velocity (U) and Density ( $\rho)$ for Diethyl Carbonate + Nitrobenzene, + Chlorobenzene, + Aniline at Different Temperatures

\begin{tabular}{|c|c|c|c|c|c|c|c|}
\hline \multirow{3}{*}{$\begin{array}{c}\text { Mole } \\
\text { fraction, } x_{1}\end{array}$} & \multicolumn{7}{|c|}{ Diethyl carbonate + nitrobenzene } \\
\hline & $293.15 \mathrm{~K}$ & $298.15 \mathrm{~K}$ & $303.15 \mathrm{~K}$ & $308.15 \mathrm{~K}$ & $313.15 \mathrm{~K}$ & $318.15 \mathrm{~K}$ & $323.15 \mathrm{~K}$ \\
\hline & \multicolumn{7}{|c|}{$\mathbf{U}(\mathbf{m} / \mathbf{s})$} \\
\hline 0.0000 & 1474.07 & 1456.26 & 1438.30 & 1420.44 & 1402.70 & 1385.13 & 1367.68 \\
\hline 0.0937 & 1447.27 & 1428.98 & 1410.67 & 1392.44 & 1374.35 & 1356.15 & 1338.01 \\
\hline 0.3577 & 1372.21 & 1353.23 & 1334.20 & 1315.29 & 1296.42 & 1277.63 & 1259.01 \\
\hline 0.4547 & 1345.12 & 1325.91 & 1306.65 & 1287.52 & 1268.35 & 1249.33 & 1230.48 \\
\hline 0.6149 & 1300.95 & 1281.27 & 1261.57 & 1241.98 & 1222.43 & 1203.00 & 1183.83 \\
\hline 0.6606 & 1288.49 & 1268.67 & 1248.79 & 1229.07 & 1209.39 & 1189.83 & 1170.60 \\
\hline \multirow[t]{2}{*}{1.0000} & 1198.01 & 1177.46 & 1156.96 & 1136.62 & 1116.45 & 1096.47 & 1076.66 \\
\hline & \multicolumn{7}{|c|}{$\rho\left(\mathrm{Kg} / \mathrm{m}^{3}\right)$} \\
\hline 0.0000 & 1202.238 & 1197.263 & 1192.297 & 1187.328 & 1182.355 & 1177.385 & 1172.408 \\
\hline 0.0937 & 1179.555 & 1174.626 & 1169.588 & 1164.553 & 1159.516 & 1154.472 & 1149.425 \\
\hline 0.1678 & 1161.679 & 1156.805 & 1151.720 & 1146.631 & 1141.539 & 1136.440 & 1131.336 \\
\hline 0.2715 & 1137.613 & 1132.465 & 1127.312 & 1122.153 & 1116.988 & 1111.812 & 1106.631 \\
\hline 0.3577 & 1117.218 & 1112.014 & 1106.804 & 1101.588 & 1096.362 & 1091.128 & 1085.885 \\
\hline 0.4547 & 1094.887 & 1089.633 & 1084.371 & 1079.102 & 1073.821 & 1068.530 & 1063.228 \\
\hline 0.6149 & 1059.198 & 1053.894 & 1048.576 & 1043.247 & 1037.908 & 1032.556 & 1027.192 \\
\hline 1.0000 & \multicolumn{7}{|c|}{$U(\mathrm{~m} / \mathrm{s})$} \\
\hline 0.0000 & 1285.71 & 1267.44 & 1248.92 & 1230.49 & 1212.19 & 1194.03 & 1175.99 \\
\hline 0.0840 & 1278.03 & 1259.44 & 1240.65 & 1221.95 & 1203.40 & 1184.95 & 1166.60 \\
\hline 0.1774 & 1269.70 & 1250.83 & 1231.85 & 1212.88 & 1194.10 & 1175.46 & 1156.89 \\
\hline 0.2682 & 1261.68 & 1242.55 & 1223.40 & 1204.26 & 1185.27 & 1166.40 & 1147.68 \\
\hline 0.3591 & 1253.71 & 1234.36 & 1215.05 & 1195.69 & 1176.51 & 1157.46 & 1138.56 \\
\hline 0.4617 & 1244.74 & 1225.17 & 1205.63 & 1186.10 & 1166.71 & 1147.48 & 1128.40 \\
\hline 0.5846 & 1233.99 & 1214.19 & 1194.41 & 1174.65 & 1155.04 & 1135.60 & 1116.30 \\
\hline 0.6290 & 1230.10 & 1210.22 & 1190.34 & 1170.50 & 1150.82 & 1131.30 & 1111.95 \\
\hline 0.7602 & 1218.65 & 1198.49 & 1178.36 & 1158.30 & 1138.42 & 1118.72 & 1099.17 \\
\hline 0.8694 & 1209.19 & 1188.83 & 1168.49 & 1148.30 & 1128.29 & 1108.46 & 1088.75 \\
\hline 1.0000 & 1198.01 & 1177.46 & 1156.96 & 1136.62 & 1116.45 & 1096.47 & 1076.66 \\
\hline
\end{tabular}


(Table 2). Continued.

\begin{tabular}{|c|c|c|c|c|c|c|c|}
\hline & \multicolumn{7}{|c|}{$\rho\left(\mathrm{Kg} / \mathrm{m}^{3}\right)$} \\
\hline 0.0000 & 1106.296 & 1100.906 & 1095.506 & 1090.093 & 1084.665 & 1079.226 & 1073.772 \\
\hline 0.0840 & 1093.551 & 1088.482 & 1083.240 & 1077.982 & 1072.811 & 1067.893 & 1062.919 \\
\hline 0.1774 & 1079.990 & 1075.030 & 1069.796 & 1064.566 & 1059.358 & 1054.330 & 1049.487 \\
\hline 0.2682 & 1067.467 & 1062.470 & 1057.263 & 1051.938 & 1046.598 & 1041.639 & 1036.561 \\
\hline 0.3591 & 1055.470 & 1050.257 & 1044.924 & 1039.576 & 1034.307 & 1029.219 & 1023.897 \\
\hline 0.4617 & 1042.065 & 1036.828 & 1031.473 & 1026.097 & 1020.901 & 1015.582 & 1010.239 \\
\hline 0.5846 & 1026.122 & 1020.863 & 1015.482 & 1010.081 & 1004.858 & 999.411 & 994.039 \\
\hline 0.6290 & 1020.399 & 1015.145 & 1009.759 & 1004.351 & 999.120 & 993.662 & 988.282 \\
\hline 0.7602 & 1003.870 & 998.694 & 993.289 & 987.861 & 982.408 & 977.031 & 971.629 \\
\hline 0.8694 & 990.570 & 985.281 & 979.863 & 974.423 & 968.857 & 963.503 & 958.042 \\
\hline \multirow[t]{3}{*}{1.0000} & 974.699 & 969.097 & 963.468 & 957.814 & 952.134 & 946.428 & 940.691 \\
\hline & \multicolumn{7}{|c|}{ Diethyl carbonate + aniline } \\
\hline & \multicolumn{7}{|c|}{$\mathbf{U}(\mathrm{m} / \mathrm{s})$} \\
\hline 0.00000 & 1656.02 & 1636.79 & 1617.52 & 1598.27 & 1579.1 & 1559.95 & 1540.88 \\
\hline 0.07302 & 1613.70 & 1594.43 & 1575.11 & 1555.80 & 1536.56 & 1517.56 & 1498.22 \\
\hline 0.16517 & 1562.65 & 1543.34 & 1523.92 & 1504.55 & 1485.25 & 1466.00 & 1446.83 \\
\hline 0.25373 & 1516.89 & 1497.74 & 1478.31 & 1458.49 & 1439.08 & 1419.76 & 1400.52 \\
\hline 0.33866 & 1475.49 & 1455.94 & 1436.36 & 1416.83 & 1397.37 & 1377.98 & 1358.67 \\
\hline 0.44318 & 1427.55 & 1407.88 & 1388.18 & 1368.52 & 1348.95 & 1329.49 & 1310.13 \\
\hline 0.54682 & 1381.13 & 1361.32 & 1341.47 & 1321.69 & 1302.02 & 1282.46 & 1263.03 \\
\hline 0.65461 & 1335.93 & 1315.96 & 1295.96 & 1276.04 & 1256.26 & 1236.61 & 1217.09 \\
\hline 0.75589 & 1294.35 & 1274.23 & 1254.09 & 1234.06 & 1214.18 & 1194.46 & 1174.87 \\
\hline 0.88404 & 1242.96 & 1222.58 & 1202.27 & 1182.09 & 1162.07 & 1142.22 & 1122.52 \\
\hline \multirow[t]{2}{*}{1.00000} & 1198.01 & 1177.46 & 1156.96 & 1136.62 & 1116.45 & 1096.47 & 1076.66 \\
\hline & \multicolumn{7}{|c|}{$\rho\left(\mathrm{Kg} / \mathrm{m}^{3}\right)$} \\
\hline 0.00000 & 1021.401 & 1017.076 & 1012.746 & 1008.41 & 1004.069 & 999.721 & 995.367 \\
\hline 0.07302 & 1018.579 & 1014.181 & 1009.775 & 1005.361 & 1000.941 & 996.514 & 992.080 \\
\hline 0.16517 & 1014.687 & 1010.192 & 1005.686 & 1001.172 & 996.647 & 992.115 & 987.571 \\
\hline 0.25373 & 1010.954 & 1006.359 & 1001.755 & 997.133 & 992.503 & 987.864 & 983.212 \\
\hline 0.33866 & 1007.334 & 1002.641 & 997.936 & 993.220 & 988.490 & 983.747 & 978.991 \\
\hline 0.44318 & 1002.841 & 998.024 & 993.191 & 988.347 & 983.487 & 978.613 & 973.723 \\
\hline 0.54682 & 997.994 & 993.047 & 988.083 & 983.104 & 978.108 & 973.097 & 968.065 \\
\hline 0.65461 & 992.838 & 987.724 & 982.646 & 977.518 & 972.372 & 967.207 & 962.023 \\
\hline 0.75589 & 987.764 & 982.535 & 977.289 & 972.022 & 966.732 & 961.426 & 956.099 \\
\hline 0.88404 & 981.296 & 975.875 & 970.438 & 964.977 & 959.494 & 953.985 & 948.452 \\
\hline 1.00000 & 974.699 & 969.097 & 963.468 & 957.814 & 952.134 & 946.428 & 940.691 \\
\hline
\end{tabular}

$\sigma\left(Y^{E}\right)=\left[\frac{\sum_{i=1}^{n}\left(Y_{\text {expt }}^{E}-Y_{c a l}^{E}\right)^{2}}{m-n}\right]^{1 / 2}$

where, $m$ is the number of experimental points, $n$ is the number of parameters, $Y_{\text {expt }}$ and $Y_{\text {cal }}$ are the experimental and calculated parameters, respectively. The values of coefficients and standard deviations at different temperatures for the above measured parameters are given in Table $\mathbf{3}$.

The excess compressibility is reported to be a quantity which is proportional to the strength of 
Table 3: Value of Coefficients, $A_{i}$, of the Redlich-Kister Polynomial and Standard Deviations, $\sigma$, for Binary Mixtures at $\mathrm{T}=(293.15,298.15,303.15,308.15,313.15,318.15$ and 323.15$) \mathrm{K}$

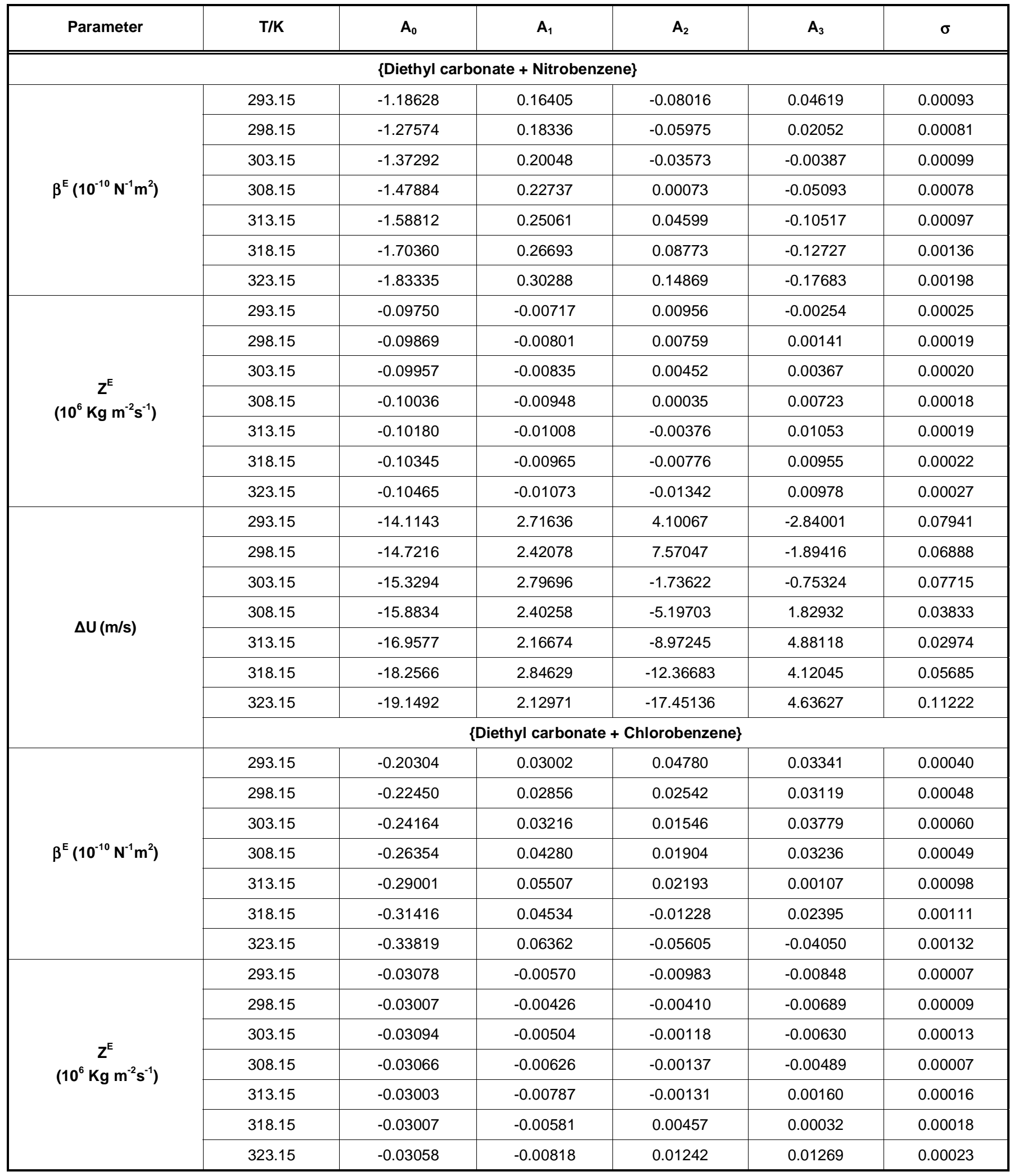


(Table 3). Continued.

\begin{tabular}{|c|c|c|c|c|c|c|}
\hline \multirow{7}{*}{$\Delta U(\mathrm{~m} / \mathrm{s})$} & 293.15 & -1.89063 & -0.38619 & -2.01288 & -0.69555 & 0.00498 \\
\hline & 298.15 & -2.80113 & -1.01793 & -2.58955 & -0.16066 & 0.01254 \\
\hline & 303.15 & -3.17176 & -0.75689 & -3.46952 & -0.84247 & 0.01994 \\
\hline & 308.15 & -4.07101 & -0.88498 & -4.00149 & -1.22564 & 0.01536 \\
\hline & 313.15 & -4.96731 & -0.89436 & -4.05773 & -1.63424 & 0.01695 \\
\hline & 318.15 & -5.89349 & -1.00034 & -4.32192 & -2.20476 & 0.02584 \\
\hline & 323.15 & -6.74481 & -1.09255 & -5.18975 & -2.91245 & 0.03266 \\
\hline & \multicolumn{6}{|c|}{ Diethyl carbonate + Aniline } \\
\hline \multirow{7}{*}{$\beta^{E}\left(10^{-10} N^{-1} m^{2}\right)$} & 293.15 & -1.08659 & 0.31255 & -0.05535 & -0.03884 & 0.00178 \\
\hline & 298.15 & -1.18733 & 0.33495 & -0.06297 & -0.03873 & 0.00178 \\
\hline & 303.15 & -1.29522 & 0.36127 & -0.07067 & -0.03347 & 0.00195 \\
\hline & 308.15 & -1.40968 & 0.39797 & -0.07446 & -0.04149 & 0.00207 \\
\hline & 313.15 & -1.53316 & 0.43268 & -0.08479 & -0.03993 & 0.00216 \\
\hline & 318.15 & -1.66582 & 0.47382 & -0.10112 & -0.05306 & 0.00243 \\
\hline & 323.15 & -1.80978 & 0.51178 & -0.10784 & -0.03690 & 0.00241 \\
\hline \multirow{7}{*}{$\begin{array}{c}Z^{E} \\
\left(10^{6} \mathrm{Kg} \mathrm{m}^{-2} \mathrm{~s}^{-1}\right)\end{array}$} & 293.15 & -0.11004 & -0.04051 & -0.00766 & 0.00573 & 0.00032 \\
\hline & 298.15 & -0.10925 & -0.03948 & -0.00708 & 0.00481 & 0.00027 \\
\hline & 303.15 & -0.10871 & -0.03893 & -0.00727 & 0.00523 & 0.00031 \\
\hline & 308.15 & -0.10850 & -0.03961 & -0.00735 & 0.00535 & 0.00032 \\
\hline & 313.15 & -0.10833 & -0.03964 & -0.00758 & 0.00539 & 0.00031 \\
\hline & 318.15 & -0.10808 & -0.04003 & -0.00641 & 0.00838 & 0.00036 \\
\hline & 323.15 & -0.10800 & -0.03947 & -0.00716 & 0.00604 & 0.00032 \\
\hline \multirow{7}{*}{$\Delta \mathrm{U}(\mathrm{m} / \mathrm{s})$} & 293.15 & -100.586 & -37.9272 & -8.06695 & 6.98964 & 0.24156 \\
\hline & 298.15 & -99.946 & -37.0429 & -7.42323 & 6.62878 & 0.23348 \\
\hline & 303.15 & -99.524 & -36.5856 & -7.25354 & 5.88761 & 0.24418 \\
\hline & 308.15 & -99.335 & -37.5375 & -7.84840 & 7.23918 & 0.24409 \\
\hline & 313.15 & -99.151 & -37.5056 & -7.72138 & 6.93625 & 0.24533 \\
\hline & 318.15 & -99.033 & -38.0965 & -6.83319 & 9.16182 & 0.27378 \\
\hline & 323.15 & -98.827 & -37.6306 & -7.51678 & 6.73862 & 0.24531 \\
\hline
\end{tabular}

interaction between unlike molecules [14]. According to Fort and Moore [15], a negative excess compressibility is an indication of strong molecular interaction in the liquid mixtures while a positive value indicates a weak interaction attributable to dispersion forces. Also the magnitude of the excess function depends on the relative strength of interaction.

Figure $\mathbf{1 a}, \mathbf{b}, \mathbf{c}$ shows the variations of $\beta^{\mathrm{E}}$ as a function of mole fraction of diethyl carbonate $x_{1}$. It can be seen that the excess adiabatic compressibility values are negative for all the mixtures over the entire range of composition at all temperatures. The variation of $\beta^{\mathrm{E}}$ with temperature is in a systematic manner. The negative values of $\beta^{\mathrm{E}}$ are found to increase with increasing temperature. The more negative value in each binary system is found to occur at $x_{1}=0.6$ indicating the formation of a stable complex between DEC and three benzene derivatives at this composition. The chemical effect includes charge transfer forces, formation of hydrogen bonds and other complex forming interactions making negative contribution towards $\beta^{\mathrm{E}}[16]$.

Generally, the excess properties are considered to be the reflecting agents of magnitude of polarity at the site of interactions in the molecules. The negative $\beta^{E}$ values decrease in the following order: DEC + Aniline > $\mathrm{DEC}$ + nitrobenzene $>\mathrm{DEC}$ + chlorobenzene. 


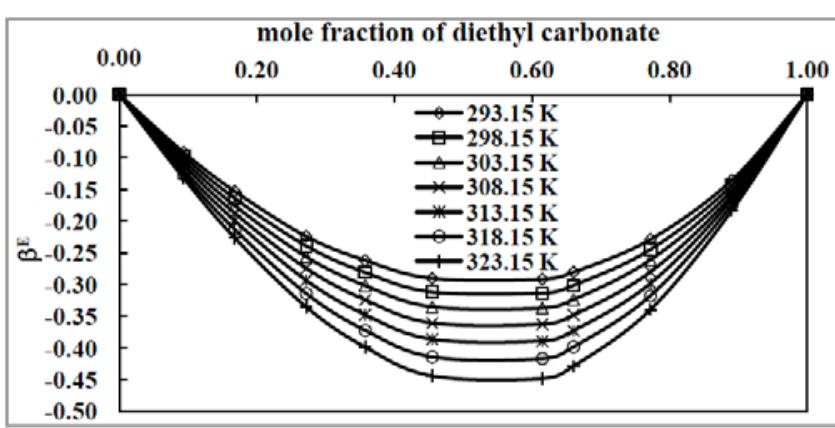

a

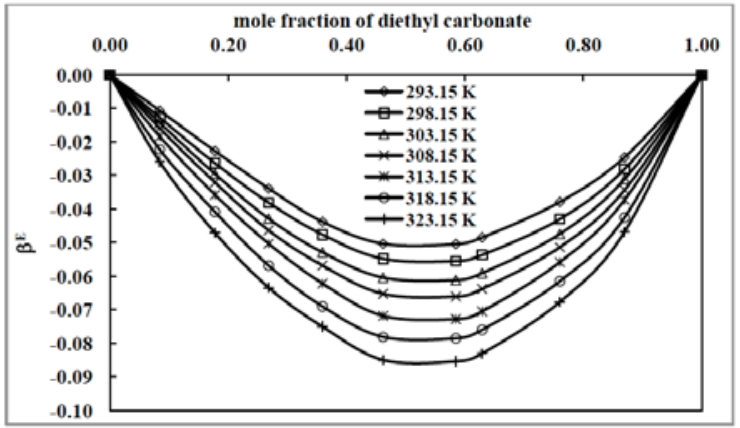

b

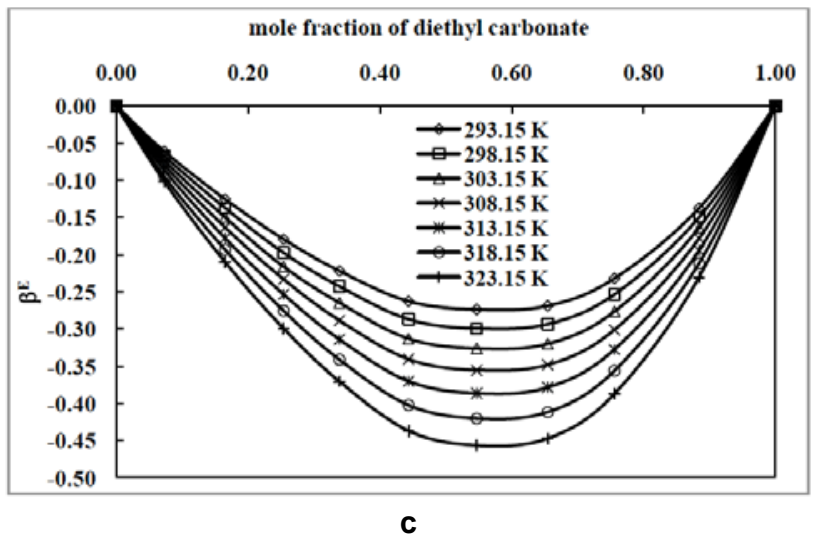

Figure 1: a: Variation of excess adiabatic compressibility $\left(\beta^{\mathrm{E}}\right)$ with mole fraction of diethyl carbonate for diethyl carbonate + nitrobenzene system at different temperatures.

b: Variation of excess adiabatic compressibility $\left(\beta^{\mathrm{E}}\right)$ with mole fraction of diethyl carbonate for diethyl carbonate + chlorobenzene system at different temperatures.

c: Variation of excess adiabatic compressibility $\left(\beta^{\mathrm{E}}\right)$ with mole fraction of diethyl carbonate for diethyl carbonate + aniline system at different temperatures.

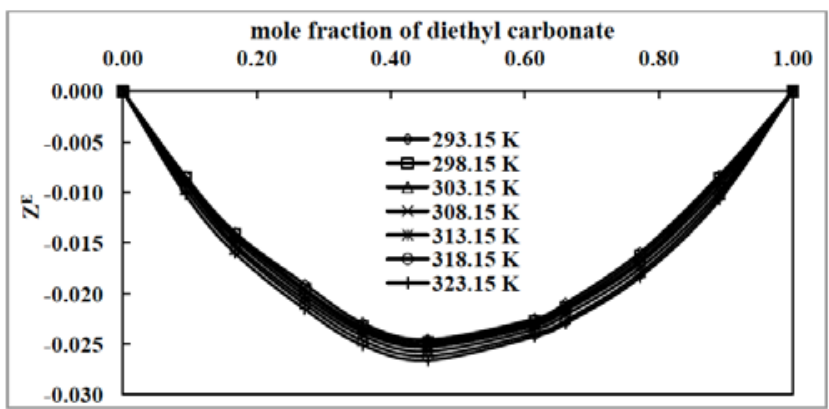

a

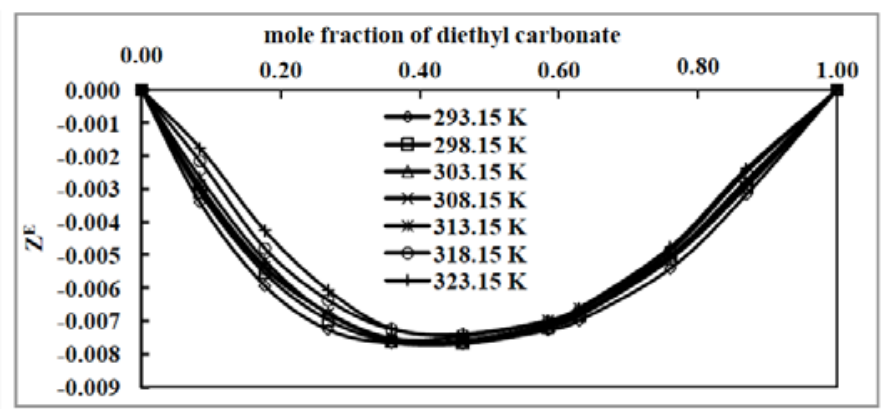

b

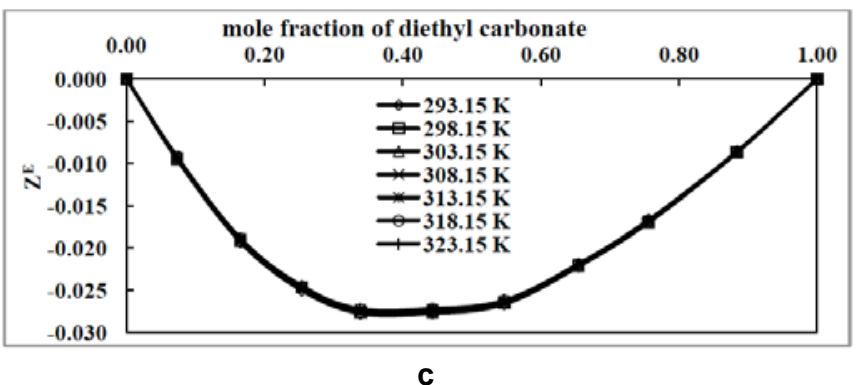

Figure 2: a: Variation of excess acoustic impedance $\left(Z^{\mathrm{E}}\right)$ with mole fraction of diethyl carbonate for diethyl carbonate + nitrobenzene system at different temperatures.

b: Variation of excess acoustic impedance $\left(Z^{\mathrm{E}}\right)$ with mole fraction of diethyl carbonate for diethyl carbonate + chlorobenzene system at different temperatures.

c: Variation of excess acoustic impedance $\left(Z^{\mathrm{E}}\right)$ with mole fraction of diethyl carbonate for diethyl carbonate + aniline system at different temperatures. 


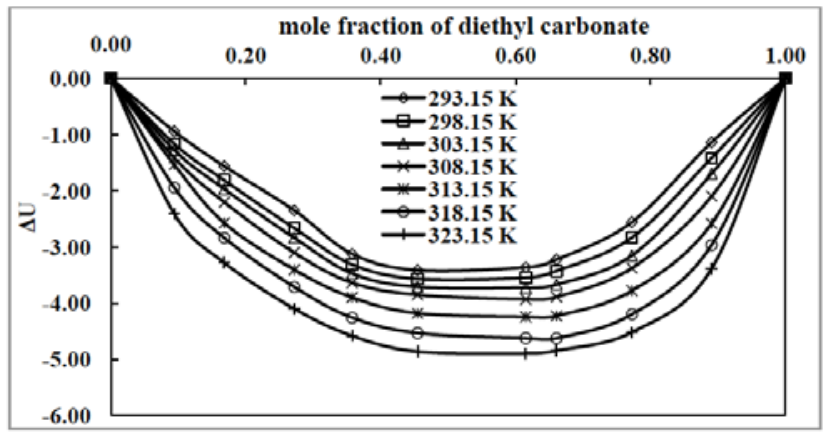

a

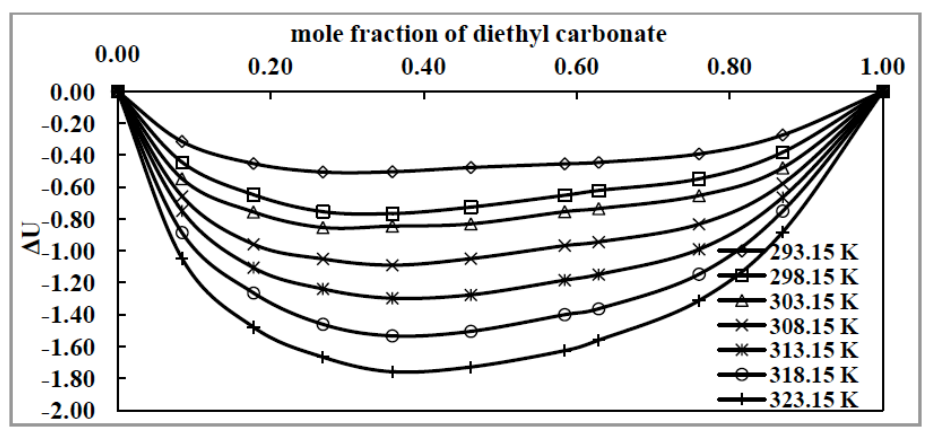

b

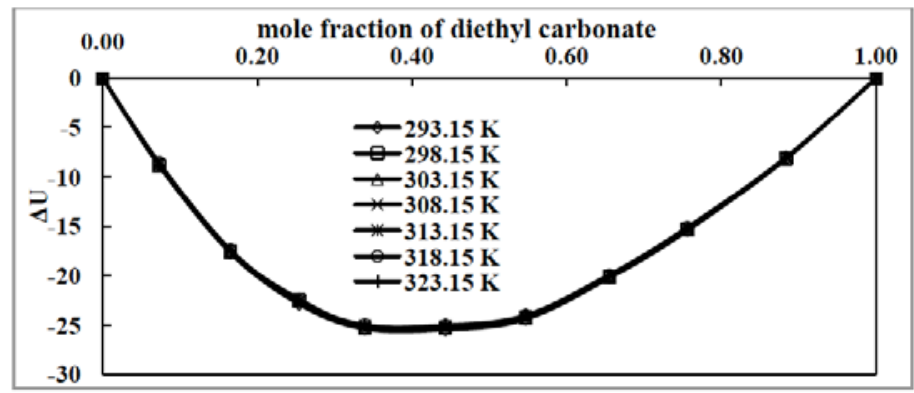

C

Figure 3: a: Variation of deviation in ultrasonic velocity $(\Delta U)$ with mole fraction of diethyl carbonate for diethyl carbonate + nitrobenzene system at different temperatures.

b: Variation of deviation in ultrasonic velocity $(\Delta U)$ with mole fraction of diethyl carbonate for diethyl carbonate + chlorobenzene system at different temperatures.

c: Variation of deviation in ultrasonic velocity $(\Delta \mathrm{U})$ with mole fraction of diethyl carbonate for diethyl carbonate + aniline system at different temperatures.

Acoustic impedance is important in the determination of acoustic transmission and reflection at the boundary of two materials having different acoustic impedance. It is also useful in the designing of ultrasonic transducers and for assessing absorption of sound in a medium.

The excess acoustic impedance, $Z^{\mathrm{E}}$ as a function of mole fraction of diethyl carbonate $x_{1}$ is presented in Figure $\mathbf{2} \mathbf{a}, \mathbf{b}, \mathbf{c}$. It is observed that the excess acoustic impedance values are negative for all the mixtures over the entire range of composition at all temperatures. The negative values of $Z^{\mathrm{E}}$ are found to increase with an increase in temperature. The change in $Z^{E}$ values with temperatureis found to be very small in case of diethyl carbonate + aniline mixture. The negative values of $Z^{\mathrm{E}}$ are in agreement with the negative values of $\beta^{\mathrm{E}}$. Based on the literature [17] it can be summarized that more than one type of interaction be present in a given system.

The $\Delta U$ values (Figure $\mathbf{3 a}, \mathbf{b}, \mathbf{c}$ ) exhibit completely negative deviation over the entire composition range for all the three systems studied. The negative $\Delta U$ may be due to the structure breaking resulting in expansion and the speeds of sound through the mixture will be slower as suggested by Reddy et al. [18]. The nature $\Delta \mathrm{U} v s . \mathrm{x}_{1}$ curves for all the mixtures in the investigated temperature interval is almost identical. It is also noticeable that the values of the excess speed of sound do not show significant variation with increments in temperature for DEC + aniline system (Figure 3c).

\section{CONCLUSION}

The values of ultrasonic velocities, densities at (293.15, 298.15, 303.15, 308.15, 313.15, 318.15 and 323.15) $\mathrm{K}$ have been determined over the entire composition range for the binary mixtures of diethyl carbonate with nitrobenzene, chlorobenzene and aniline. From the experimental data excess adiabatic compressibility, excess acoustic impedance and deviation in ultrasonic velocity have been calculated. The excess values and deviations are observed to be negative for all the mixtures at all the temperatures studied. The Redlich-Kister equation has been used to estimate the parameters and standard deviations.

\section{REFERENCES}

[1] Singh A, Saxena SK, Saxena MC. Dielectric relaxation in $\mathrm{OH}-\mathrm{O}$ bond complexes. Phys Chem Liq 1983; 12: 329-336. http://dx.doi.org/10.1080/00319108308084562 
[2] Pandey JD, Soni NK, Dey R, Verma R. Excess functions of binary mixtures at varying pressures. Fluid Phase Equilib 2004; 215: 17-22. http://dx.doi.org/10.1016/j.fluid.2003.06.004

[3] Shukla D, Singh S, Parveen S, Gupta M, Shukla JP. Thermodynamical properties of binary mixtures of methanol with chlorobenzene and bromobenzene from $293 \mathrm{~K}$ to $313 \mathrm{~K}$. Int J Thermophys 2008; 29: 1376-84. http://dx.doi.org/10.1007/s10765-008-0444-7

[4] Shukla RK, Shukla SK, Pandey VK, Awasthi P. Sound velocity, effective temperature and pseudo-Gruneisen parameters of $\mathrm{Pb}-\mathrm{Sn}$ mixtures at elevated temperatures. $\mathrm{J}$ Phys Chem Liq 2007; 45: 169-80. http://dx.doi.org/10.1080/00319100601126794

[5] Sudhamsa B, SarathBabu M, Narendra K. Study on thermodynamic properties of binary mixtures of diethyl carbonate with benzonitrile, benzaldehyde at different temperatures. Int Lett Chem Phys Astron 2014; 19: 1-7. http://dx.doi.org/10.18052/www.scipress.com/ILCPA.38.1

[6] Gayol A, Ladia MC, Alfonsina EA, Raquel EM, Jose LL. Volumetric properties of (dialkyl carbonate +n-alkane) mixtures at high pressures: experimental measurement and Nitta-Chao model prediction. J Chem Thermodyn 2013; 58: 245-53.

http://dx.doi.org/10.1016/j.jct.2012.11.011

[7] Balasaheb RA, Machhindra KL, Nilesh NW, Dnyaneshwar SW. Viscosities, ultrasonic velocities at (288.15 and 298.15) $\mathrm{K}$, and refractive indices at (298.15) $\mathrm{K}$ of binary mixtures of 2,4,6-trimethyl-1,3,5-trooxane with dimethyl carbonate, diethyl carbonate and propylene carbonate. J Chem Eng Data 2006; 51: 68-72.

http://dx.doi.org/10.1021/je050183a

[8] Ratnam MV, Sudhir M, Nandini M. Excess properties of diethyl carbonate + ketone binary mixtures at variable temperatures: Application of PFP theory to excess volumes. J Mol Liq 2013; 177: 229-36.

http://dx.doi.org/10.1016/j.molliq.2012.10.038

[9] Joshi SS, Aminabhavi TM, Ramachandra HB, Shukla SS. Densities and viscosities of binary liquid mixtures of nitrobenzene with cyclohexane and N,N-dimethylformamide. J Chem Eng Data 1990; 35: 185-7. http://dx.doi.org/10.1021/je00060a027
[10] Thirumaran S, Savithri S. Ultrasonic investigation in ternary liquid mixtures of substituted benzenes with acetophenone at different temperatures. J Ind Chem Soc 2010; 87: 279-87.

[11] Ali A, Tariq M. Thermodynamic and transport behavior of binary liquid mixtures of benzyl alcohol with monocyclic aromatics at $303.15 \mathrm{~K}$. J Mol Liq 2006; 128: 50-5. http://dx.doi.org/10.1016/j.molliq.2005.09.002

[12] Alonso I, Mozo I, De La Fuente IG, Gonzalez JA, Cobos JC. Thermodynamics of ketone + amine mixtures Part V. Volumetric and speed of sound data at $(293.15,298.15$ and 303.15) $\mathrm{K}$ for mixtures of 2-Heptanone with aniline, $\mathrm{N}$ Methylaniline or Pyridine. J Solution Chem 2011; 40: 205771.

http://dx.doi.org/10.1007/s10953-011-9774-3

[13] Redlich O, Kister AT. Algebraic representation of thermodynamic properties and the classification of solutions. Ind Eng Chem 1948; 40: 345-8. http://dx.doi.org/10.1021/ie50458a036

[14] Kiyohara O, Grolier J-PE, Benson GC. Excess volumes, ultrasonic velocities, and adiabatic compressibilities for binary cycloalkanol mixtures at $25^{\circ} \mathrm{C}$. Can J Chem 1974 ; 52 : 2287-93.

http://dx.doi.org/10.1139/v74-330

[15] Fort RJ, Moore WR. Adiabatic compressibilities of binary liquid mixtures. Trans Faraday Soc 1965; 61: 2102-11. http://dx.doi.org/10.1039/tf9656102102

[16] Narendra K, Srinivasu Ch, Fakruddin SK, Narayanamurthy $P$. Excess parameters of binary mixtures of anisaldehyde with o-cresol, m-cresol and p-cresol at $\mathrm{T}=(303.15,308.15$, 313.15 and 318.15) K. J Chem Thermodyn 2011; 43: 160411. http://dx.doi.org/10.1016/j.jct.2011.05.018

[17] Nath G, Sahu S, Paikaray R. Study of acoustic parameters of binary mixtures of a non-polar liquid with polar liquid at different frequencies. Indian J Phys 2009; 83: 429-36. http://dx.doi.org/10.1007/s12648-009-0024-0

[18] Reddy Y, Naidu PS, Prasad KR. Ultrasonic study of acetophenones in the binary-mixtures containing isopropanol as common component. Indian J Pure Appl Phys 1994; 32: 958-63. 